\title{
Evaluation of Antifungal Activity of Methacrylic Acid incorporated in Conventional Heat-activated Resins
}

\author{
${ }^{1}$ Lokendra Gupta, ${ }^{2} \mathrm{IN}$ Aparna, ${ }^{3} \mathrm{~B}$ Dhanasekar, ${ }^{4}$ Sujatha Bhat, ${ }^{5}$ Kishore Ginjupalli, ${ }^{6}$ Priyanka Agarwal
}

\section{ABSTRACT}

Aim: The aim of this study was to evaluate the antifungal activity of heat-activated denture base resins modified with different concentrations of methacrylic acid (MAA).

Materials and methods: Methyl methacrylate (MMA) monomer of heat-activated resins was modified with different concentrations of MAA $(0,15,20$, and $25 \%)$ for the preparation of specimens to evaluate antifungal activity of heat-activated resins. Prepared specimens were stored in distilled water at $37^{\circ} \mathrm{C}$ for 1 day and 1 week before the evaluation of microbial adhesion. Microbial adhesion of Candida albicans cells to acrylic samples was examined under light microscopy after Gram staining of all the acrylic samples. Data were subjected to one-way analysis of variance followed by post-hoc Tukey's honest significant difference test. A value of $p<0.05$ was considered to be statistically significant.

Results: Addition of MAA to the MMA monomer was found to significantly reduce the adhesion of $C$. albicans for all the groups. Reduction of $C$. albicans cell adherence was found significant for all three groups (I, II, and III) as compared to control, both at 1 day $(p<0.001)$ and 1 week $(p<0.001)$ after storage in distilled water.

Conclusion: Addition of MAA to conventional denture base formulations reduced the adhesion of $C$. albicans. This method of incorporating antifungal property to denture base resins can effectively be used to reduce denture stomatitis in elderly and immunocompromised patients.

Keywords: Candida albicans, Denture stomatitis, Methacrylic acid, Methyl methacrylate.

How to cite this article: Gupta L, Aparna IN, Dhanasekar B, Bhat S, Ginjupalli K, Agarwal P. Evaluation of Antifungal Activity of Methacrylic Acid incorporated in Conventional Heat-activated Resins. World J Dent 2017;8(2):129-133.

\footnotetext{
${ }^{1-3}$ Department of Prosthodontics and Crown \& Bridge, Manipal College of Dental Sciences, Manipal, Karnataka, India

${ }^{4}$ Department of Microbiology, Melaka Manipal Medical College Manipal, Karnataka, India

${ }^{5}$ Department of Dental Materials, Manipal College of Dental Sciences, Manipal, Karnataka, India

${ }^{6}$ Department of Pedodontics and Preventive Dentistry, Manipal College of Dental Sciences, Manipal, Karnataka, India

Corresponding Author: INAparna, Department of Prosthodontics and Crown \& Bridge, Manipal College of Dental Sciences Manipal, Karnataka, India, Phone: +08202922183, e-mail: aparna. narayan@manipal.edu
}

\section{Source of support: Nil}

Conflict of interest: None

\section{INTRODUCTION}

The most commonly used denture base material in dentistry is based on polymethyl methacrylate (PMMA). This material exhibits excellent esthetics, good compressive and tensile strength, low water sorption and is cost-effective to enumerate few desirable properties. Nevertheless, they are prone to microbial adhesion, commonly Candida albicans ${ }^{1,2}$ leading to a condition, known as denture stomatitis. ${ }^{3,2}$ Candida albicans is an opportunistic fungal pathogen constituting around $80 \%^{4}$ of healthy oral microflora. Despite being an opportunistic pathogen, its presence is limited to superficial mucosal surfaces due to IgG and IgA immunoglobulins, anti-Candida activities of polymorphonuclear leukocytes, and macrophages. ${ }^{5}$ The oral temperature of $37^{\circ} \mathrm{C}$ is also considered as an inhibiting factor for their pathogenicity in most of the Candidal species in oral mucosa. ${ }^{6}$ However, in any person with compromised immunity, it can transform to a pathogen. ${ }^{5}$ It is classified as type I(localized simple infection with pinpoint hypermia), type II (erythematous type), and type III (granular type). Type III is considered severe form of denture stomatitis.?

According to Wilson, ${ }^{8}$ the prevalence of denture stomatitis ranges from 25 to $65 \%$ while Gendreau and Loewy. ${ }^{9}$ found the prevalence between 15 and $70 \%$. According to him, elderly denture wearer and women's are more affected than males. ${ }^{9}$ Other than conditions causing compromised immunity, the growth of Candida is aided by other factors, such as denture trauma, impaired salivary flow and salivary gland function, poor denture hygiene, continuous and night time wearing of dentures, accumulation of denture plaque, bacterial, and yeast contamination on denture surfaces. ${ }^{9}$

Other than Candida species, microorganisms, such as Streptococcus sanguinis, Streptococcus salivarius, Streptococcus mutans, Fusobacterium nucleatum, and Actinomyces viscosus have also been responsible to cause denture stomatitis. ${ }^{10,11}$

Denture stomatitis, caused by the wearing of acrylic dentures, has been ascribed to poorly fitting dentures, unbalanced occlusion, and fungal infection with Candida strains. Control and prevention of this disease have been tried using various modalities, including meticulous oral hygiene, disinfection with various disinfecting solutions ${ }^{12,13}$ 
microwave energy ${ }^{14}$ and altering the surface energy of denture base resins. ${ }^{15}$

Several antifungal agents have been used to prevent Candida growth onto the denture base resin surfaces and tissue conditioner surfaces. ${ }^{16}$

Initial treatment by topical application of antifungal agents is widely accepted as the treatment of choice. ${ }^{17}$ Nystatin, fluconazole, itraconazole, and amphotericin $B^{18,19}$ were used as an additive or as a topical ointment against Candida growth. Several materials have been incorporated in acrylic resins as antimicrobial agents to reduce the microbial adhesion. ${ }^{12,20-26}$ Laser phototherapy and low-level laser therapy are also proven to be effective treatment options to reduce denture stomatitis. ${ }^{27,28}$

Methacrylic acid (MAA) is a colorless, viscous carboxylic acid liquid soluble in most organic solvents. It is manufactured industrially on a large scale as a precursor to its esters, especially Methyl methacrylate (MMA). This carboxylic acid is helpful in disinfecting external as well as internal portions of the acrylic resin by its property to create net effective negative charge. ${ }^{29,30}$ Authors proved that the systems containing MAA are less cytotoxic and can be used in the oral cavity. ${ }^{31,32}$ The purpose of this study was to evaluate the antifungal activity of different concentrations of MAA as a comonomer additive to MMA against $C$. albicans cell adherence to denture base resins.

\section{MATERIALS AND METHODS}

Commercially available heatcure denture base resin was procured from Dental Products of India, Mumbai, India. Methacrylic acid of $97 \%$ purity was purchased from Burgoyne Burbidges and Co., Mumbai, India. Standard strains of C. albicans (ATCC10231) were procured from HiMedia Laboratories, Mumbai, India. The study was divided into four groups based on the percentage of MAA: 0, 15, 20, and 25\%, namely control, groups I, II, and III respectively, for two-time intervals, viz., at 1 day and 1 week. The study was performed aseptically in a laminar airflow cabinet hood to avert cross contamination.

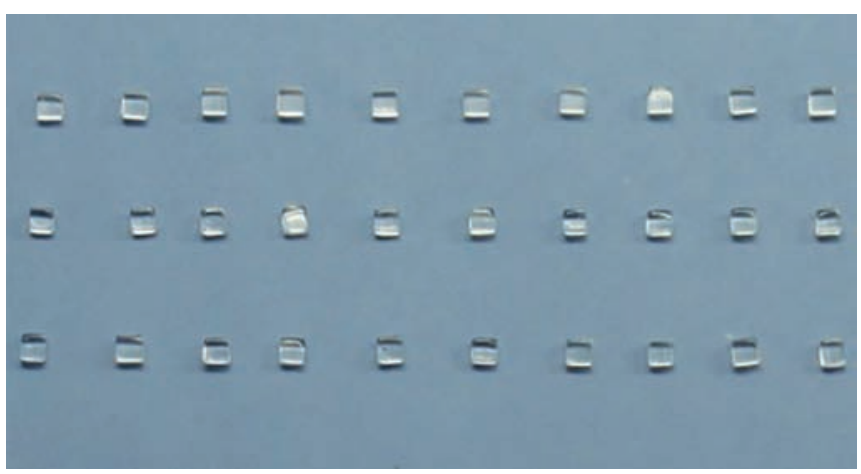

Fig. 1: Prepared samples of acrylic resin to evaluate C. albicans adhesion

\section{RESIN SAMPLE PREPARATION}

Wax patterns were fabricated in dimensions of $5 \times 5 \times$ $3 \mathrm{~mm}^{3}$ in a silicon mold. Prepared wax patterns were invested and dewaxed to make a plaster mold in a dental flask for sample preparation. Comonomer preparation was done by mixing MMA and MAA in appropriate ratio as per the groups in a closed container. Samples were prepared by mixing polymer and comonomer at 2.5:1 ratio by volume. The proportioned material was then enclosed in a ceramic cup until the mixture reached dough stage at which time it was packed into the plaster mold. The mold along with the packed dough was then transferred to a water bath at room temperature after bench curing for 30 minutes. Polymerization cycle was initiated by raising the temperature of water bath to $74^{\circ} \mathrm{C}$ in 30 minutes, and the same temperature was maintained for 8 hours. At the end of 8 hours, the temperature of the water bath was increased to $100^{\circ} \mathrm{C}$ and maintained for 30 minutes. ${ }^{33}$ The mold was then bench cooled after which the specimens were retrieved, finished, and polished $(n=5)$. The polished samples were then rinsed and stored in distilled water for 1 day and 1 week at $37^{\circ} \mathrm{C}$ to simulate oral condition and to remove any residual monomer after polymerization (Fig. 1). All the samples were sterilized with $2 \%$ chlorhexidine ${ }^{34}$ and washed with sterilized deionized water to remove chlorhexidine residues.

\section{Measurement of Adhesion of $C$. albicans}

Inoculum for $C$. albicans was prepared with sabouraud dextrose broth and incubated at $37^{\circ}$. The brain heart infusion (BHI) broth volume was maintained with a suspension and turbidity equivalent to a McFarland standard of 0.5. $5 \mathrm{~mL}$ of $\mathrm{BHI}$ broth for each sample was transferred to individual test tubes and inoculated with prepared inoculum of C. albicans. Prepared acrylic blocks were introduced individually (using a sterile pointed forceps) into the test tubes containing $5 \mathrm{~mL}$ of $\mathrm{BHI}$ broth with C. albicans inoculum (Fig. 2). Subsequently, the test

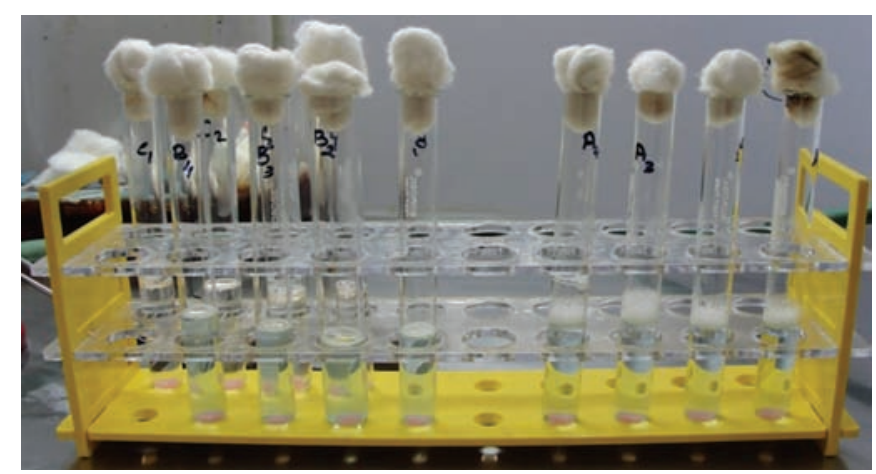

Fig. 2: Resin samples with $C$. albicans inoculum in $\mathrm{BHI}$ broth 


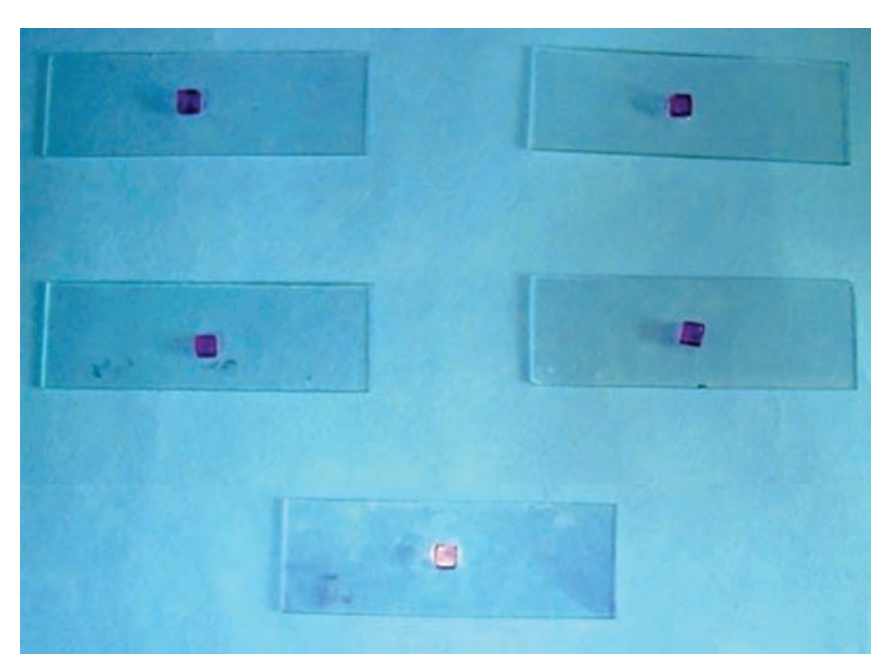

Fig. 3: Gram-stained resin samples

tubes were incubated at $37^{\circ} \mathrm{C}$ aerobically for 18 hours. After incubation, the samples from each test tube were removed and washed with sterile $\mathrm{BHI}$ broth to remove nonadherent $C$. albicans cells. Following this, the acrylic samples were gently passed over a flame to fix the adherent cells. Samples were then air-dried and stained using Gram's staining technique (Fig. 3). The stained samples were washed with deionized water. Microscopic examination of the stained samples was carried out under oil immersion microscope (×1000 magnification, Olympus CX41, USA), as suggested by Park et al. ${ }^{24}$ The number of Gram-positive budding yeast cells was counted for a

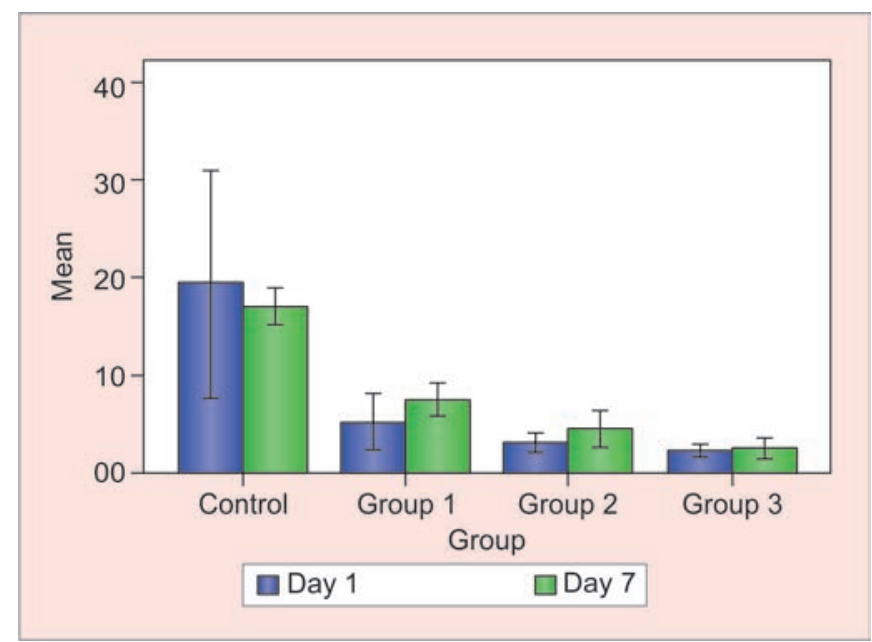

Graph 1: Effect of different percentages of methacrylic acid, incorporated into acrylic resin specimens on the adherence of C. albicans cells at 1 and 7 day. Error bars represent standard deviations among the groups minimum of 10 microscopic fields, and the mean value of the 10 fields was calculated for statistical analysis.

\section{RESULTS}

\section{Evaluation of Adhesion of $C$. albicans}

Mean and standard deviation values of the adherence of C. albicans to the PMMA surface with and without MAA are presented in Graph 1 and Table 1. The control group showed highest number of adhering cells of C. albicans at 1 day and 1 week, whereas groups I, II, and III showed great reduction of $C$. albicans yeast cells as compared to control group at 1 day $(<0.001)$ and 1 week $(<0.001)$ interval (Figs 4A to D). Reduction of C. albicans yeast cells was found statistically insignificant between groups I, II, and III when compared to each other at 1 day. However, the reduction was statistically significant between groups I and II $(p<0.015)$ and groups I and III $(p<0.001)$ at 1 week. There was statistically insignificant difference between groups II and III ( $p=0.134)$.

\section{Statistical Analysis}

Descriptive analysis was performed to evaluate the mean value and standard deviation of the C. albicans adherence using Statistical Package for the Social Sciences 20.0. Multiple comparisons among the groups were done using post-hoc Tukey's honest significant difference (HSD) test.

\section{DISCUSSION}

The microbial constitution of the oral cavity is very diverse, and they do not cause disease in healthy patients. However, in elderly and immunocompromised patients, even microbes constituting the normal flora can cause diseases. To avoid accumulation of such microorganisms, denture surfaces have been modified to reduce their potential adhesion and colonization. Such attempts are realized by adding antimicrobial additives to denture base formulations in the form of comonomers. In this study, MAA has been added as a comonomer to a denture base resin formulation to diminution, the adhesion of C. albicans cells on the acrylic resin surface.

Commercially available denture base resin (Dental products of India, Mumbai, India) was modified with MAA instead of fabricating a new resin formulation as attempted by Park et al. ${ }^{1}$ In contrast to the study by

Table 1: Comparisons of adhesion of $C$. albicans among the groups at 1 day and 1 week

\begin{tabular}{lllllr}
\hline Time interval & Control (O\% MAA) & Group 1 (15\% MAA) & Group 2 (20\% MAA) & Group 3 (25\% MAA) & $p$-value \\
\hline 1 day & $19.40 \pm 9.28$ & $5.4 \pm 2.30$ & $3.2 \pm 0.836$ & $2.4 \pm 0.54$ & $<0.001$ \\
7 day & $17.0 \pm 1.58$ & $7.6 \pm 1.3416$ & $4.6 \pm 1.52$ & $2.6 \pm 0.89$ & $<0.001$ \\
\hline
\end{tabular}

**p-values computed using the analysis of variance followed by post-hoc Tukey's HSD test. C. albicans: Candida albicans; MAA: Methacrylic acid 


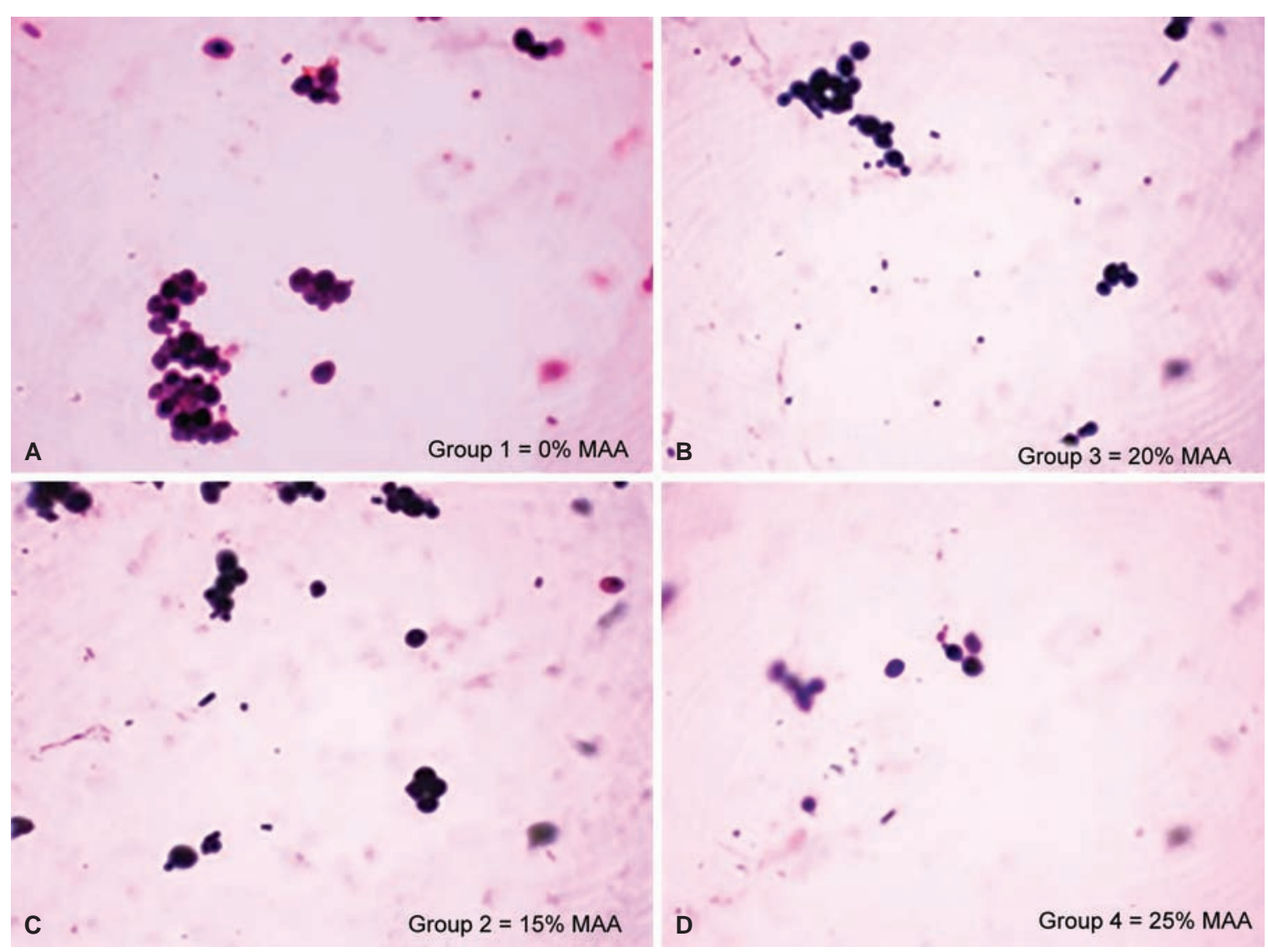

Figs 4A to D: Reduction of $C$. albicans cells on acrylic surfaces with increasing concentration of methacrylic acid

Park et $\mathrm{al}^{1,24}$ higher concentrations of MAA and a longer period of evaluation of Candidal adhesion were done to investigate the inhibitory effect of MAA on C. albicans. It was noticed that the inhibitory effect of MAA was more evident at higher concentrations and lingered for a longer duration (7 days). Various factors are involved in the initial adhesion of Candida to denture base surfaces, which include surface charge, surface free energy, hydrophobicity, and roughness. ${ }^{35}$ The adhesion of C. albicans to the denture surface can be understood by electrostatic interaction and hydrophobic properties. The negatively charged C. albicans surfaces have repulsive action with negatively charged denture base materials. However, hydrophobic interactions of denture base surfaces and C. albicans can promote microbial growth ${ }^{24}$ because electrostatic interaction is secondary to hydrophobic interaction since the adherence process takes place even in the presence of repulsive forces. ${ }^{36}$ Incorporation of different materials to denture base resins can change their electrostatic or hydrophobic properties and may be helpful in preventing Candida adherence. According to Park et al, ${ }^{37}$ increased level of MAA contributed the greatest ionic charge on the denture surfaces. These high levels of ionic charges are responsible for reduction of Candida cells on modified denture base resins. In this study, there was a decreasing trend of Candida cell adhesion to the modified denture base resins at both the time intervals, viz., 1 day and 1 week. This study emphasized that MAA can be used even in commercially available resins apart from being used in a new formulation of resins as done in an earlier study. ${ }^{1}$

\section{CONCLUSION}

This study divulges the antifungal effect of MAA in heatactivated resins against $C$. albicans at 1 day, and that it sustained even by day 7. This antifungal activity of MAA in denture base resins can be implemented in elderly and systemically ill patients, where opportunistic pathogens, like Candida can lead to chronic inflammation in the form of denture stomatitis. However, being an in vitro study, its results should be carefully extrapolated for clinical use. Further studies, preferably long-term clinical trials, need to be carried out to substantiate the results of this study.

\section{REFERENCES}

1. Park SE, Periathamby AR, Loza JC. Effect of surface-charged poly(methyl methacrylate) on the adhesion of Candida albicans. J Prosthodont 2003 Dec;12(4):249-254.

2. Webb BC, Thomas CJ, Willcox MD, Harty DW, Knox KW. Candida-associated denture stomatitis. aetiology and management: a review. Part 3. treatment of oral candidosis. Aust Dent J 1998 Aug;43(4):244-249.

3. Ramage G, Tomsett K, Wickes BL, López-Ribot JL, Redding SW. Denture stomatitis: a role for Candida biofilms. 
Oral Surg Oral Med Oral Pathol Oral Radiol Endod 2004 Jul;98(1):53-59.

4. Williams D, Lewis M. Pathogenesis and treatment of oral candidosis. J Oral Microbiol 2011 Jan 28;3.

5. Jenkinson, HF.; Douglas, LJ. Interactions between Candida species and bacteria in mixed infections. In: Brogden KA, Guthmiller JM, editors. Polymicrobial diseases [Internet]. Washington DC: ASM Press; 2002 [cited 2012]. Chapter 18. Available from: http://www.ncbi.nlm.nih.gov/books/ NBK2486.

6. Schauer F, Hanschke R. Taxonomy and ecology of the genus Candida. Mycoses 1999;42(Suppl 1):12-21.

7. Newton AV. Denture sore mouth: a possible aetiology. Br Dent J 1962 May;112:357-360.

8. Wilson J. The aetiology, diagnosis and management of denture stomatitis. Br Dent J 1998 Oct 24;185(8):380-384.

9. Gendreau L, Loewy ZG. Epidemiology and etiology of denture stomatitis. J Prosthodont 2011 Jun;20(4):251-260.

10. Arendorf TM, Walker DM. Denture stomatitis: a review. J Oral Rehabil 1987 May;14(3):217-227.

11. Casemiro LA, Gomes Martins CH, Pires-de-Souza Fde C, Panzeri H. Antimicrobial and mechanical properties of acrylic resins with incorporated silver-zinc zeolite - Part I. Gerodontology 2008 Sep;25(3):187-194.

12. Yilmaz H, Aydin C, Bal BT, Ozçelik B. Effects of disinfectants on resilient denture-lining materials contaminated with Staphylococcus aureus, Streptococcus sobrinus, and Candida albicans. Quintessence Int 2005 May;36:373-381.

13. da Silva FC, Kimpara ET, Mancini MN, Balducci I, Jorge AO, Koga-Ito CY. Effectiveness of six different disinfectants on removing five microbial species and effects on the topographic characteristics of acrylic resin. J Prosthodont 2008 Dec;17(8):627-633.

14. Dixon DL, Breeding LC, Faler TA. Microwave disinfection of denture base materials colonized with Candida albicans. J Prosthet Dent 1999 Dec;81(2):207-214.

15. Moura JS, da Silva WJ, Pereira T, Del Bel Cury AA, Rodrigues Garcia RC. Influence of acrylic resin polymerization methods and saliva on the adherence of four Candida species. J Prosthet Dent 2006 Sep;96(3):205-211.

16. Marra J, Paleari AG, Rodriguez LS, Leite AR, Pero AC, Compagnoni MA. Effect of an acrylic resin combined with an antimicrobial polymer on biofilm formation. J Appl Oral Sci 2012 Nov-Dec;20(6):643-648.

17. Zarb, GA.; Bolender, CL.; Eckert, SE. Prosthodontic treatment for edentulous patients: complete dentures and implantsupported prostheses. 12th ed. St. Louis: Mosby; 2004;38-39.

18. Chow CK, Matear DW, Lawrence HP. Efficacy of antifungal agents in tissue conditioners in treating candidiasis. Gerodontology 1999 Dec;16(2):110-118.

19. Thomas CJ, Nutt GM. The in vitro fungicidal properties of Visco-gel, alone and combined with nystatin and amphotericin B. J Oral Rehabil 1978 Apr;5(2):167-172.

20. Cunha TR, Regis RR, Bonatti MR, de Souza RF. Influence of incorporation of fluoroalkyl methacrylates on roughness and flexural strength of a denture base acrylic resin. J Appl Oral Sci 2009 Mar-Apr;17(2):103-107.

21. Dhir G, Berzins DW, Dhuru VB, Periathamby AR, Dentino A. Physical properties of denture base resins potentially resistant to Candida adhesion. J Prosthodont 2007 NovDec;16(6):465-472.

22. Kuroki K, Hayashi T, Sato K, Asai T, Okano M, Kominami Y, Takahashi Y, Kawai T . Effect of self-cured acrylic resin added with an inorganic antibacterial agent on Streptococcus mutans. Dent Mater J 2010 May;29(3):277-285.

23. Paleari AG, Marra J, Pero AC, Rodriguez LS, Ruvolo-Filho A, Compagnoni MA. Effect of incorporation of 2-tert-butylaminoethyl methacrylate on flexural strength of a denture base acrylic resin. J Appl Oral Sci 2011 May-Jun;19(3):195-199.

24. Park SE, Blissett R, Susarla SM, Weber HP. Candida albicans adherence to surface-modified denture resin surfaces. J Prosthodont 2008 Jul;17(5):365-369.

25. Pesci-Bardon C, Fosse T, Serre D, Madinier I. In vitro antiseptic properties of an ammonium compound combined with denture base acrylic resin. Gerodontology 2006 Jun;23(2): 111-116.

26. Shibata T, Hamada N, Kimoto K, Sawada T, Sawada T, Kumada H, Umemoto T, Toyoda M . Antifungal effect of acrylic resin containing apatite-coated $\mathrm{TiO} 2$ photocatalyst. Dent Mater J 2007 May;26(3):437-444.

27. Simunović-Soskić M, Pezelj-Ribarić S, Brumini G, Glazar I, Grzić R, Miletić I. Salivary levels of TNF-alpha and IL-6 in patients with denture stomatitis before and after laser phototherapy. Photomed Laser Surg 2010 Apr;28(2):189-193.

28. Maver-Biscanin M, Mravak-Stipetic M, Jerolimov V. Effect of low-level laser therapy on Candida albicans growth in patients with denture stomatitis. Photomed Laser Surg 2005 Jun;23(3):328-332.

29. Hogt AH, Gregonis DE, Andrade JD, Kim SW, Dankert J, Feijen J. Wettability and $\zeta$ potentials of a series of methacrylate polymers and copolymers. J Colloid Interface Sci 1985;106(2):289-298.

30. Lin JJ, Cameron SM, Runyan DA, Craft DW. Disinfection of denture base acrylic resin. J Prosthet Dent 1999 Feb;81(2): 202-206.

31. Yamarik T, Escobar A, Andersen F. Final report of the safety assessment of methacrylic acid. Int J Toxicol 2005;24: 33-51.

32. Torres-Lugo M, García M, Record R, Peppas NA. Physicochemical behavior and cytotoxic effects of $\mathrm{p}$ (methacrylic acid-g-ethylene glycol) nanospheres for oral delivery of proteins. J Control Release 2002 Apr 23;80(1-3):197-205.

33. Anusavice, KJ, editor. Phillips' science of dental materials. 10th ed. Philadelphia, PA: WB Saunders; 1996. p. 249.

34. Altieri KT, Sanitá PV, Machado AL, Giampaolo ET, Pavarina AC, Vergani CE. Effectiveness of two disinfectant solutions and microwave irradiation in disinfecting complete dentures contaminated with methicillin-resistant Staphylococcus aureus. J Am Dent Assoc 2012 Mar;143(3):270-277.

35. Pereira-Cenci T, Del Bel Cury AA, Crielaard W, Ten Cate JM. Development of Candida-associated denture stomatitis: new insights. J Appl Oral Sci 2008 Mar-Apr;16(2):86-94.

36. Gross M, Cramton SE, Götz F, Peschel A. Key role of teichoic acid net charge in Staphylococcus aureus colonization of artificial surfaces. Infect Immun 2001 May;69(5):3423-3426.

37. Park SE, Chao M, Raj PA. Mechanical properties of surfacecharged poly (methyl methacrylate) as denture resins. Int J Dent 2009;2009:841431. 